\title{
Effect of time-of-day specific obese training on body composition and physical capacity
}

\author{
Mohamed Ali Khanfir ${ }^{1}$, Walid Bouaziz ${ }^{1}$, Liwa Masmoudi ${ }^{1}$, Hassen Ben \\ Aouicha $^{1}$, Fathia kobbi ${ }^{2}$, Houda Drira ${ }^{2}$, Neila Abid $^{2}$ \\ ${ }^{1}$ Higher Institute of Sport and Physical Education Sfax (Tunisia) \\ ${ }^{2}$ University Medical Center Hédi Chaker Sfax (Tunisia)
}

\begin{abstract}
The best strategy for management of obese, outside pharmacological interventions, is physical exercise associated to diet. Recent research has discovered that the problem of obesity is largely due to a biological clock and that lipid oxidation is higher in the evening compared to the morning and at night compared to day. The purpose of this study is to investigate the effect of time-of-day specific obese training on body composition and physical capacity in obese following a low calorie diet. 20 sedentary pre-obese and obese with a mean BMI of $34.3 \mathrm{~kg} / \mathrm{m}^{2}$ aged 20 to 47 years subjects participated in a concurrent strength and specific endurance training for obese. Subjects were divided into two training groups: a Morning training Group (MG: $n=10)$ and an Evening training Group $(E G: n=10)$. The specific training associated to lower caloric diet has increased physical capacity (17,7\% for EG and 15,6\% for $M G)$, decreased body weight $(7,3 \%$ for EG and $6 \%$ for $M G)$ fat percentage (19,5\% for $E G$ and $11,3 \%$ for $M G)$ and waist circumference $(10,2 \%$ for $E G$ and $8,2 \%$ for $M G)$ in both groups. Afternoon training was more effective than morning training on fat loss (24.9\% for EG versus $15.9 \%$ for $M G$ ) and on lean mass variation $(+2.9 \%$ for $E G$ versus $-0.5 \%$ for $M G)$.
\end{abstract}

Keywords: Obesity, Time of day Training, physical capacity, Body Composition

\section{Introduction}

The global epidemic of overweight and obesity has become a major health, social and economical burden with 312 million people worldwide being obese [BMI (body mass index) $\geq 30 \mathrm{~kg} / \mathrm{m}^{2}$ ] and at least 1,1 billion people being overweight (BMI 25-29.9 $\mathrm{kg} / \mathrm{m}^{2}$ ) [1] [2]. The obesity treatment must be adapted to the disease evolutionary stage and the dominant complications [3] [4] [5] [6]. The treatment of obesity can associate several methods: diet, behavioral therapy, drug therapy, surgery and physical exercise [7]. In the literature it appears that the best strategy to manage overweight or obese subjects, outside pharmacological interventions, is the association of diet and physical exercise [8] [9] [10] [11]. Associating diet and physical exercise is the best form of treatment to induce weight loss in overweight or obese individuals in the first weeks, followed by physical exercise to maintain weight loss [12]. Physical exercise is included in most treatment programs for overweight patients or obese because its energy expenditure causes weight loss [13] [14] [15].

In addition to diet, physical activity has a significant effect on metabolism, it decreases the basal metabolic rate and increases resting metabolic rate permitting healthy weight loss by preserving lean mass [11]. This metabolic action includes reducing insulin resistance by improving the use of energy substrates by the muscle [16]. Otherwise, some of the metabolic and hormonal variables that affect fat oxidation are regulated by circadian rhythms [17]. A. Chwalibog et al. [18] indicated that during the day, carbohydrates are the major oxidative fuel, while during the night, changes in the energy status are accommodated by increasing fat oxidation. R.A Salata et al. [19] reported greater release of ACTH in the afternoon than in the morning.

Recent research has found that the problem of obesity is related to a biological clock and that lipid metabolism has a biological rhythm during the day through lipolysis and lipogenesis [20] [21]. In a recent study, H. Mohebbi et al. [17] revealed that time of day affects significantly the maximal fat oxidation (Fat max) in obese and normal-weight subjects. They found that the measured Fat max in the evening is higher than in the morning in obese and in normal-weight subjects.

Knowing one hand that greatest benefits of physical qualities training are achieved when it coincides at the acrophase of the correspondent qualities [22] and secondly that maximal fat oxidation in exercise is in the evening [17], we believe that training in the evening for the obese may be more effective than training in the morning. To our knowledge no study has been devoted to the effect of the time-of-day training on physical capacity, body weight and body composition in obese.

Therefore, the purpose of this study was to determinate the effect of time-of-day specific training on body composition and physical fitness in pre-obese and obese assigned to an energy restricted diet. 


\section{2-1 Subjects}

\section{Materials and Methods}

20 sedentary subjects ( 12 men and 8 women) pre-obese and obese with a mean BMI of $34.3 \mathrm{~kg} / \mathrm{m}^{2}$ aged 20 to 47 years who have no heart, respiratory or orthopedic disease participated voluntarily in this study. We preferred to work only with obese, but the protocol constraints lead us to take two pre-obese subjects. This option was already selected in this kind of study to keep satisfactory number of participants. The subjects' chronotype determination was carried out by the self-assessment questionnaire of J.A. Horne and O. Östberg [23]. The subjects chosen for this study were neither of morning nor of evening. Participants were randomly assigned to one of two groups of 10 subjects (6 males and 4 females in each group): an (MG) group who had training in the morning between $07: 00 \mathrm{~h}$ and 08:30 $\mathrm{h}$ and an (EG) group who had training in the evening between 17:00 $\mathrm{h}$ and 18:30 $\mathrm{h}$.

Tab. 1: Characteristics of the study subjects

\begin{tabular}{lccc}
\hline \multicolumn{1}{c}{ Parameters } & $\begin{array}{c}\text { Morning Group } \\
(\mathrm{N}=10)\end{array}$ & $\begin{array}{c}\text { Evening Group } \\
(\mathrm{N}=10)\end{array}$ & {$[$ Min $;$ Max $]$} \\
\hline Age (years) & $31,2 \pm 8,1$ & $28,4 \pm 8$ & {$[20 ; 47]$} \\
Height $(\mathrm{m})$ & $1,68 \pm 0,11$ & $1,68 \pm 0,11$ & {$[1,51 ; 1,87]$} \\
Weight $(\mathrm{kg})$ & $97,1 \pm 15$ & $96,7 \pm 17,8$ & {$[65,9 ; 120,9]$} \\
BMI $\left(\mathrm{kg} / \mathrm{m}^{2}\right)$ & $34,3 \pm 4,3$ & $34,3 \pm 5,6$ & {$[28,9 ; 48,5]$} \\
\hline
\end{tabular}

\subsection{Diet}

At the beginning of the study all subjects were invited to the endocrinology department of the university medical center Hédi Chaker of Sfax to complete one week recall questionnaire. The subjects' food intakes during the last week were recorded. Then their energy intakes were calculated using Bilnut 2.01 software package (SCDA Nutrisoft, Cerelles, France) and the food composition tables published by the Tunisian National Institute of Statistics in 1978. The diet prescribed for each participant was containing 30\% calories less than previous caloric level calculated by the software. This low calorie diet prescribed was balanced with an average of $15 \%$ protein, $30-35 \%$ fat and $50-55 \%$ carbohydrates. Both groups had a similar dietary monitoring with an initial consultation in the beginning of the protocol, a second visit in the middle and a third one in last sessions of the protocol in the endocrinology service.

\subsection{Training protocol}

Eight weeks of one session concurrent strength and aerobic endurance training was recommended to the subjects by a frequency of three sessions a week. The aerobic endurance program consisted in 60 minutes of brisk walking at $65 \%$ of the heart rate reserve (HRR). The pace of walking increased during training to keep the same level of cardiac solicitation. The strength training follows the endurance training in every session. It includes three exercises: abdominal crunch, oblique crunch and back crunch Tab 2. Subjects were instructed to do 3 series of 10 repetitions (increased by 5 repetitions every 15 days) with a 30 seconds break between series. At the end of the session, stretching exercises for $5 \mathrm{~min}$ are done by the subjects.

$\mathrm{Tab} 2$. The instructions of prescribed exercises for the participants

\begin{tabular}{|cl|}
\hline Exercises & \multicolumn{1}{c|}{ Instructions } \\
\hline $\begin{array}{c}\text { Abdominal } \\
\text { crunches }\end{array}$ & $\begin{array}{l}\text { Lie on the back on the exercise mat and keep your knees flexed. Then while your feet are hips } \\
\text { width apart and are on the floor, lift your head, neck and shoulders off floor. }\end{array}$ \\
\hline $\begin{array}{c}\text { Oblique } \\
\text { crunches }\end{array}$ & $\begin{array}{l}\text { Lie on the back on the exercise mat and place the left knee on the right knee. Then while the } \\
\text { hands are behind the head, rise the head and upper body of the mat and move toward to tour left. }\end{array}$ \\
\hline Back crunches & $\begin{array}{l}\text { Lie on your front on the exercise mat with your arms stretched out in front of you (fingers } \\
\text { pointed) and your legs together (toes pointed). Then carefully lift your arms, chest and legs off the } \\
\text { floor. Hold this position about one second before returning to the start position. }\end{array}$ \\
\hline
\end{tabular}

\subsection{Body measurements}

At the beginning of the study and after 8 weeks training, all subjects were evaluated by measuring their height, body weight, body composition and waist circumference. For height measurement, all subjects removed their shoes and stood erect with heels together, took a deep breath, and held it. Subjects stood with head level 
looking straight ahead. The height of subjects was then recorded in centimeters [24]. Total body weight and body composition (fat mass, lean mass and fat percentage) were measured using validated [25] body composition analyzer (Tanita TBF 300) with an accuracy of $0,1 \mathrm{Kg}$ in body weight and $0,1 \%$ in fat percentage. Waist circumference (WC in $\mathrm{cm}$ ), being used as a marker of central body fat [26], was measured with a nondeformable tape ruler between the lower rib margin and the iliac crest, at the end gentle-expiration (as recommended by international guidelines).

\subsection{Fitness test}

To assess the obese fitness, we were limited to the 6-minutes walk test which was validated in obese men and women to measure their physical ability seen its high correlation with $\mathrm{VO}_{2 \max }$ and quality of life [27] [28]. It was conducted according to the proposed protocol of the American Thoracic Society (ATS) [29].

The 6-MWT consists on browsing the greatest distance possible in $6 \mathrm{~min}$, by making round trips on 30 $\mathrm{m}$ distance, while keeping a walking speed as regular as possible (without running). Patients are encouraged every minute using standardized sentences, and at the same time we announce the elapsed time. A familiarization test is performed 10 minutes before the test run of 6 minutes.

The 6-minute walk test took place always at the same hour, between $07 \mathrm{~h}$ and $8.30 \mathrm{~h}$ for MG and between $17 \mathrm{~h}$ and $18.30 \mathrm{~h}$ for EG, before and after the training program. A heart rate monitor (Polar T61) permitted to record the measured heart rate of the test subjects before and during the 6-MWT.

\subsection{Statistics}

All statistical analysis was performed using STATISTICA analysis software (Version 6.1, StatSoft, France). Data is reported as the mean $\pm \mathrm{SD}$ (standard deviation) within the text and table, and displayed as the mean \pm SE (standard error) in the figure. The Shapiro-Wilk W-test of normality revealed that data was normally distributed. A paired Student's t-test was used to determine the significance of differences between pre- and post-training. The mean percent change from baseline $[100 *(\mathrm{~T} 1-\mathrm{T} 0) / \mathrm{T} 0]$ are calculated. Differences between groups after training were analyzed using analysis of covariance, with baseline values used as covariates and the group used as the independent variable. A p value of less than 0.05 was considered statistically significant.

\section{1: Effect of time of day training on the physical capacity \\ III. Results}

The effect of time of day training on the physical capacity in MG and EG is reported in fig. 1. Both groups increased significantly $(\mathrm{p}<.001)$ the distance traveled in the 6 MWT by $15.6 \%$ and $17.7 \%$ respectively in $\mathrm{MG}$ and $\mathrm{EG}$.

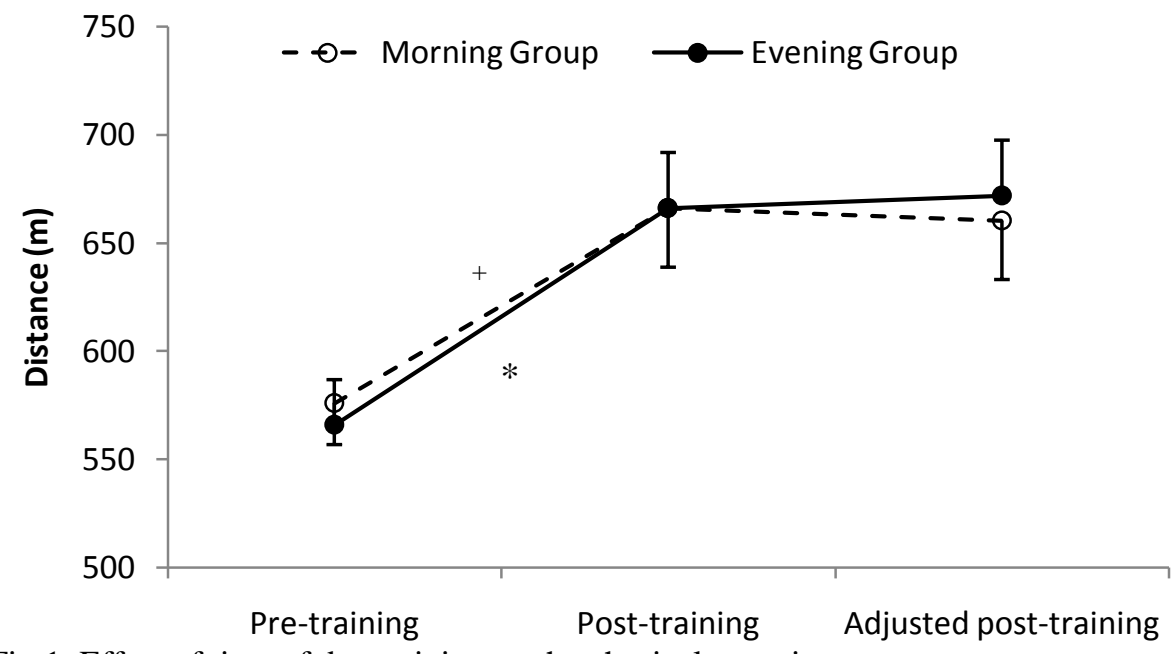

Fig 1: Effect of time of day training on the physical capacity

+ Significantly different from pre-training at $\mathrm{p}<.001$ for the morning group

* Significantly different from pre-training at $\mathrm{p}<.001$ for the evening group

\section{2: Effect of time of day training on body mass and BMI}

The effect of time of day training on the body mass and BMI in MG and EG is reported in fig. 2. Body mass for both groups decreased significantly $(\mathrm{p}<.001)$ by $6 \%$ and $7.3 \%$ respectively for MG and EG. Similarly, BMI for the two groups decreased significantly $(\mathrm{p}<.001)$ by $5.8 \%$ and $7.1 \%$ in $\mathrm{MG}$ and $\mathrm{EG}$ respectively. 
a)

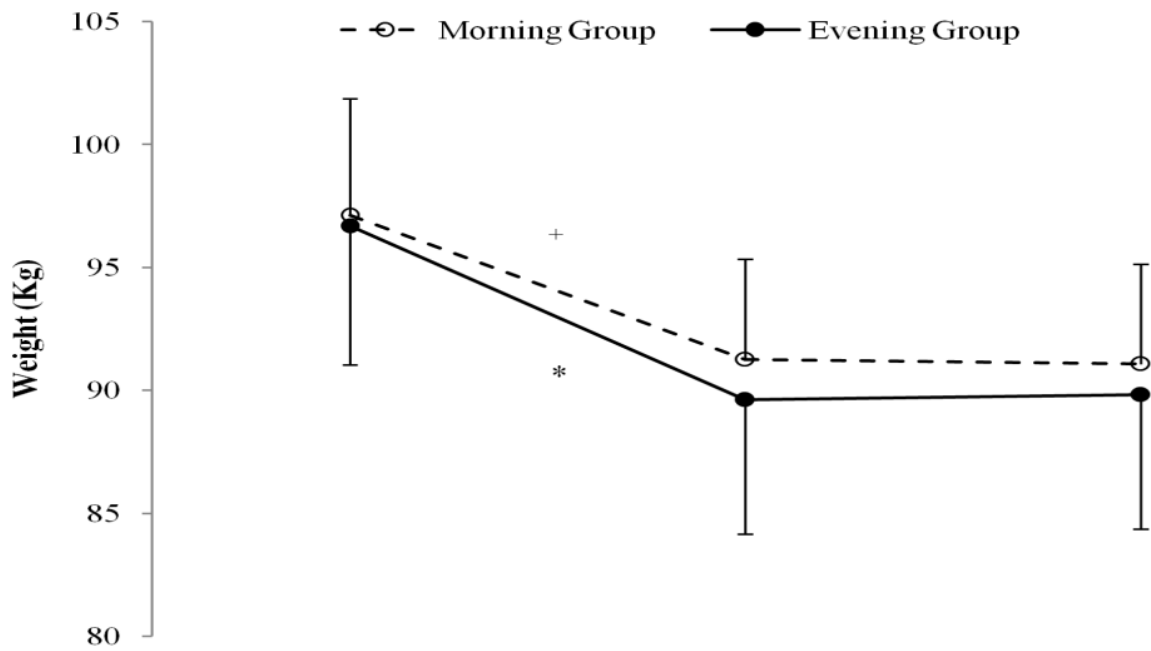

b)

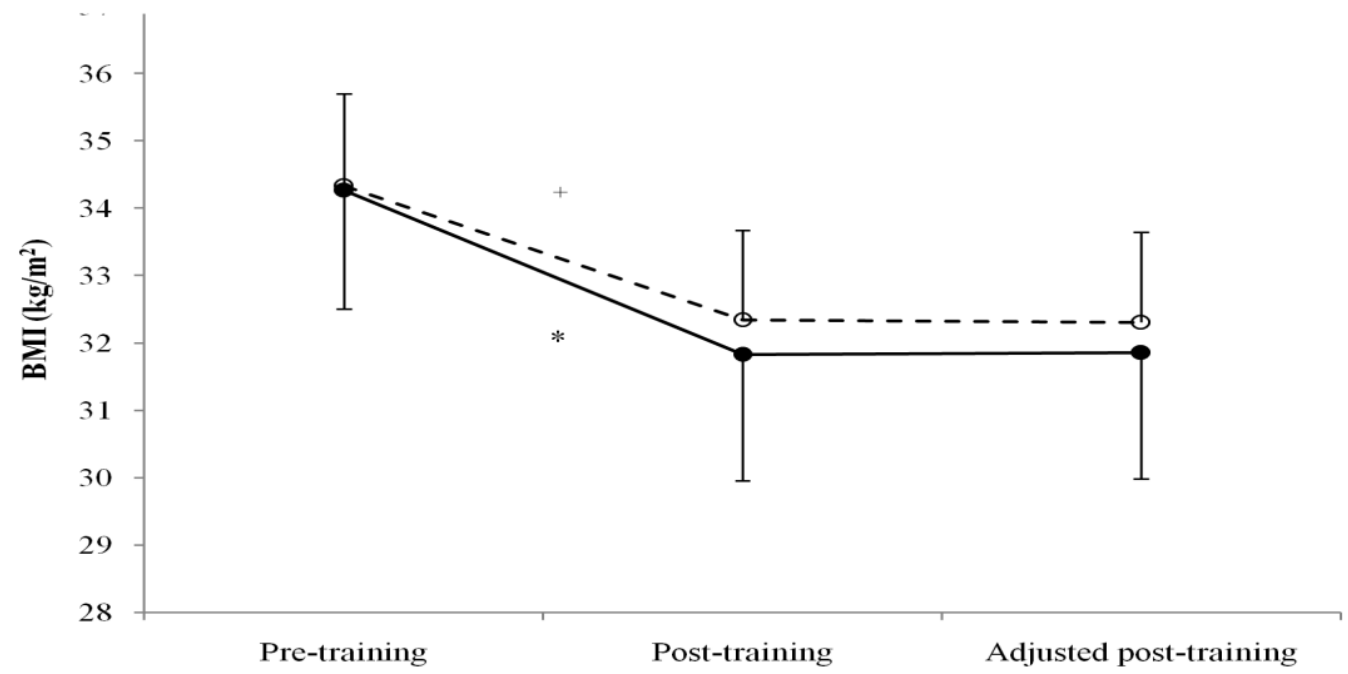

Fig 2: Effect of time of day training on body mass (a) and BMI (b)

+ Significantly different from pre-training at $\mathrm{p}<.001$ for the morning group

* Significantly different from pre-training at $\mathrm{p}<.001$ for the evening group

\section{3: Effect of time of day training on fat mass and percentage of fat}

The effect of time of day training on fat mass and percentage of fat is reported in fig. 3. Fat mass for the both groups decreased significantly $(\mathrm{p}<.001)$ by $15.9 \%$ and $24.9 \%$ respectively for MG and EG. Similarly, percentage of fat for the two groups decreased significantly by $11.3 \%$ and $19.5 \%$ for MG and EG respectively. ANCOVA showed greater decrease of fat mass $(p=.026)$ and percentage of fat $(p=0.008)$ in EG compared with MG. 
a)

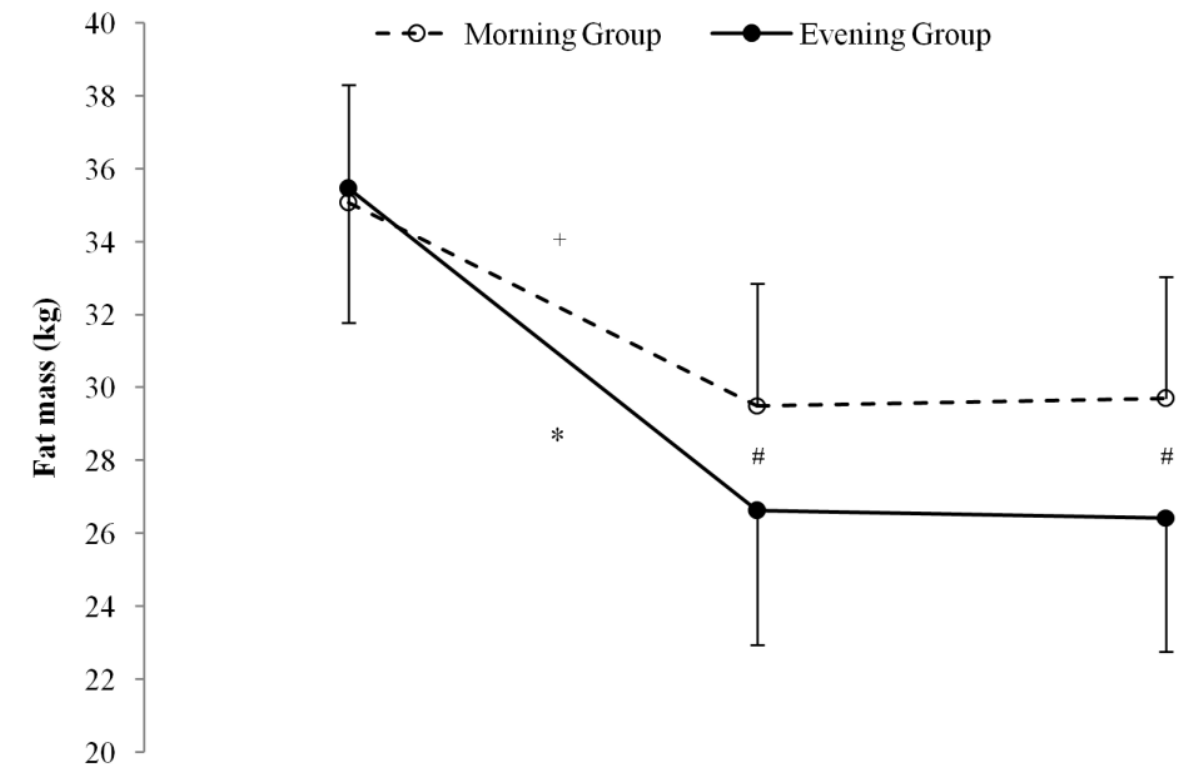

b)

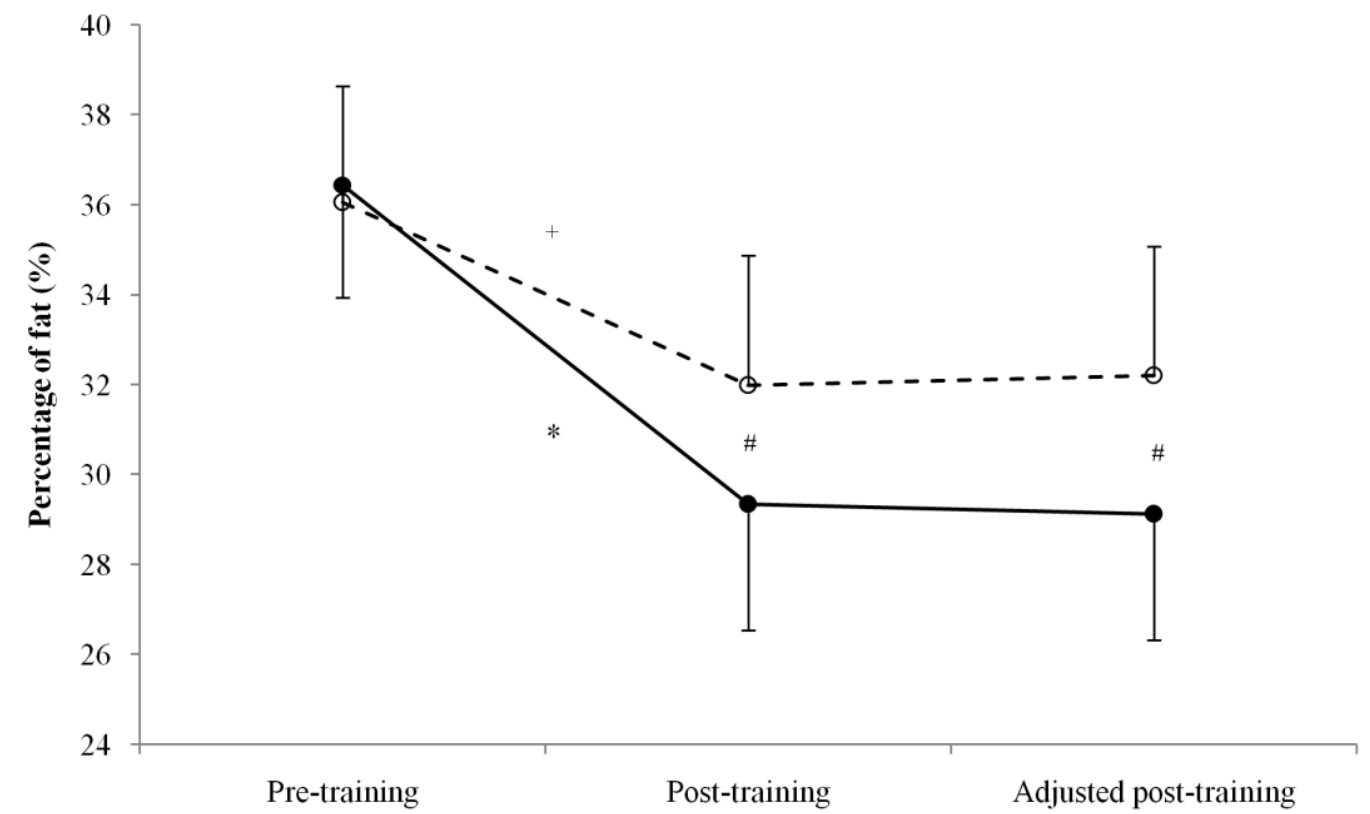

Fig 3: Effect of time of day training on fat mass (a) and percentage of fat (b) + Significantly different from pre-training at $\mathrm{p}<.001$ for the morning group

* Significantly different from pre-training at $\mathrm{p}<.001$ for the evening group \# Significantly different from the morning group at $\mathrm{p}<0.05$

\section{4: The effect of time of day training on the lean body mass}

The effect of time of day training on the lean body mass of MG and EG is reported in fig. 4. The lean body mass for MG decrease insignificantly $(\mathrm{p}=.75)$ by $0.5 \%$, however it increase significantly $(\mathrm{p}<.001)$ by $2.9 \%$ for EG. ANCOVA showed a significant difference $(\mathrm{p}=.033)$ of lean fat mass with adjusted post-training in EG compared with MG. 


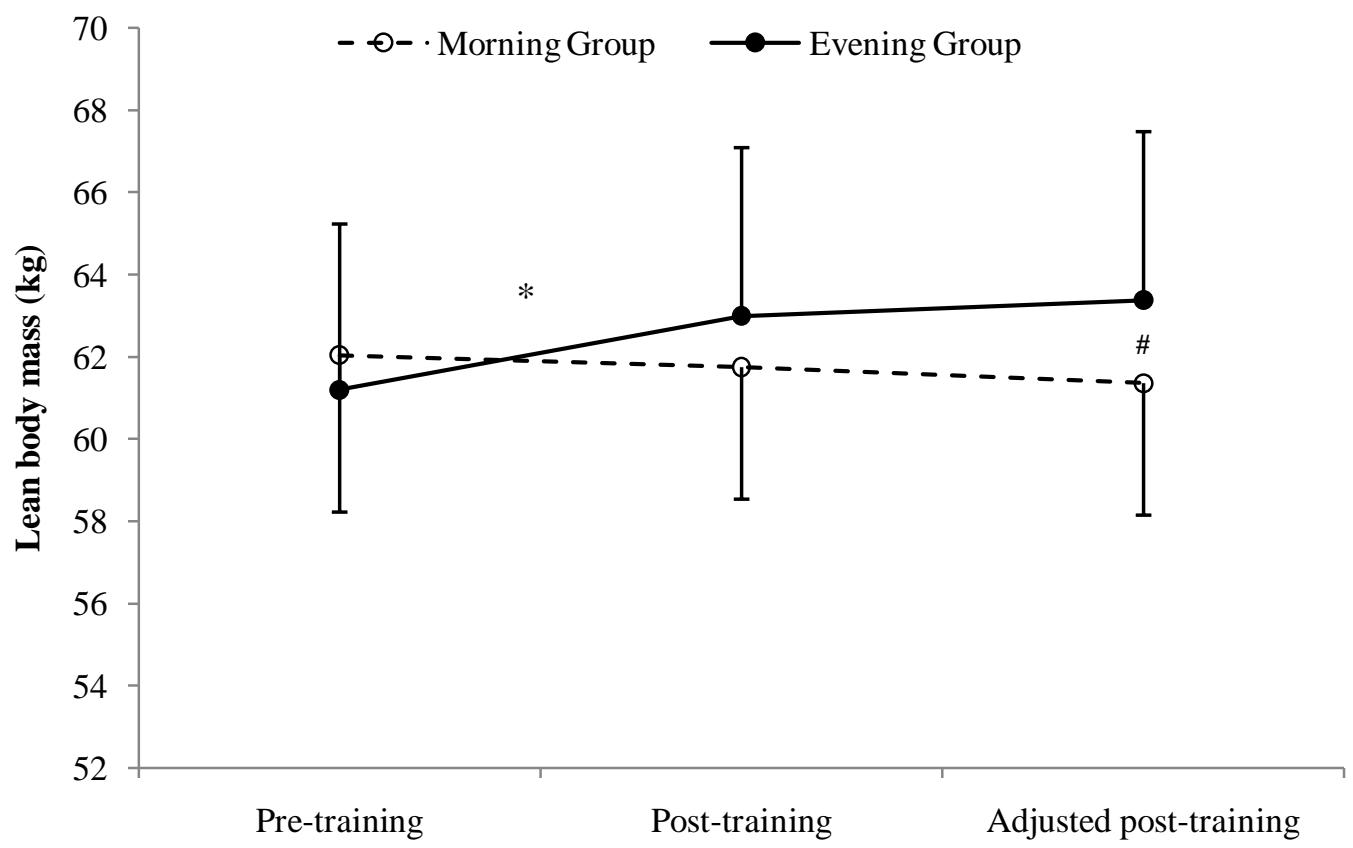

Fig 4: The effect of time of day training on the lean body mass

* Significantly different from pre-training at $\mathrm{p}<.001$ for the evening group

\# Significantly different from the morning group at $\mathrm{p}<0.05$

\section{5: Effect of time of day training on the waist circumference}

The effect of time of day training on the waist circumference of MG and EG is reported in fig. 5. Waist circumference of both groups decreased significantly $(\mathrm{p}<.001)$ by $8.2 \%$ and $10.2 \%$ respectively in MG and EG.

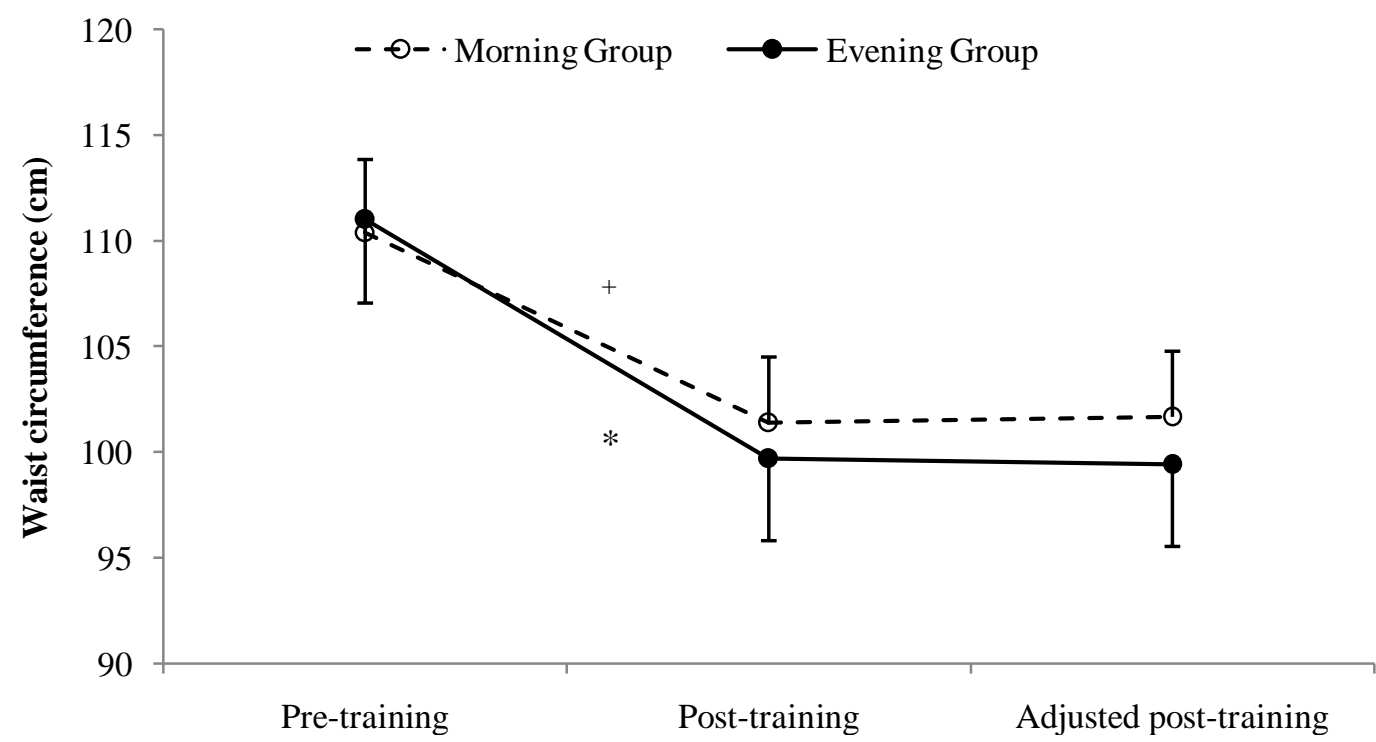

Fig 5: Effect of time of day training on the waist circumference

+ Significantly different from pre-training at $\mathrm{p}<.001$ for the morning group

$*$ Significantly different from pre-training at $\mathrm{p}<.001$ for the evening group

\section{Discussion}

The main purpose of this study was to explore the effect of time of day specific training in obese. The results showed that evening specific training is more effective than morning specific training in body composition. Fat mass decreased more significantly in EG (24,9\%) than in MG (15,9\%). A significant improvement in lean body mass in EG by $2,9 \%$ was observed versus a stabilization and a trend towards a 
reduction in MG. Both groups had similar lean body mass in the beginning of the study but after training EG had significant more lean body mass than MG.

In this study, we have chosen to associate physical exercise to a restricted calorie diet to optimize the effect of the training program. This restrictive diet of $30 \%$ is the most prescribed diet in association with physical activity [30] [31] [32] [33] [34]. It permits more weight loss than more restrictive diet that can be quickly abandoned [35]. As a means of reducing total body-fat mass, it is generally accepted that a dietary regimen is easier and more effective than exercise alone [36] However, it has been reported that dietary treatment also reduces skeletal muscle mass [37] and is less effective in improving insulin resistance than exercise [38]. After a Meta-analyzes of literature, B. Schaar et al [12] concluded that physical exercise had beneficial effects in overweight and obese subjects. However, when it comes to inducing weight loss, physical exercise combined with changes in diet is the most effective form of treatment. Now, it is established that appropriate diet and physical activity are the most significant modalities with minimum complications in the prevention and treatment of obesity [39].

Concerning the training program, we opted to one session concurrent aerobic endurance and strength training. This choice is based on the recommendations of the American College of Sports Medicine [40] and the World Health Organization [41] which provide that both endurance training and strength training should be a part of obese and pre-obese management. For endurance training we chose aerobic endurance training at $65 \%$ of HRR during 60 minutes [42] as a moderate intensity exercise. The intensities used for obese endurance training in literature go from low intensities selected by obese themselves [43] [44] to $80-90 \%$ of $\mathrm{HR}_{\max }$ [45].

Although high-intensity exercise results in a lower percentage of fat oxidation during the exercise sessions, it is important to highlight that it is the total amount of fat oxidized that determines weight loss. In line with this, isocaloric training programs at 45 and $85 \%$ of $\mathrm{VO}_{2 \max }$ caused the same reductions in body fat and weight despite more fat (in percentage) being oxidized in the low-intensity group during the exercise sessions [46]. This is explained by the continued fat oxidation during the restitution phase; the higher the intensity of the exercise, the higher the fat oxidation post-exercise [47] [48]. With moderate intensity exercise during 60 minutes, we consider that the most amount of energy expenditure occurs during exercise and few amount later at resting. The strength training proposed to obese might leads to increase of lean body mass, muscle strength and power in one hand and decrease of body fat percentage, waist circumference, visceral and subcutaneous abdominal and thigh fat thickness on the other hand [49] [50] [51] [52]. Interestingly, it has also been found that the resting metabolism is higher after strength training than endurance training with low or moderate intensity [41] .This mean that strength training that we combined with moderate endurance training will increase the low amount of fat oxidation post exercise due to the moderate endurance training.

About training effect, the physical capacity of EG and MG has increased after training. The distance travelled in the 6 MWT has increased by $95 \mathrm{~m}$ for the MG and $100 \mathrm{~m}$ for the EG. This increase is much higher than the $56 \mathrm{~m}$ of increase reported by S. Ghroubi et al [53] after similar training combined with diet. Relative lower intensity and advancing subject age of S. Ghroubi et al [53] study can explain a part of differences. Time of day training has no effect on physical capacity measured by the 6 MWT.

Body mass decreased with similar proportions in both groups. The decrease of body mass measured in this study is $5,8 \mathrm{Kg}$ for MG and 7,3 for EG. This decrease in body mass is reflected on subjects' BMI which decreased by $2 \mathrm{Kg} / \mathrm{m}^{2}(5,8 \%)$ in $\mathrm{MG}$ and $2,4 \mathrm{Kg} / \mathrm{m}^{2}(7,1 \%)$ in EG. No significant effect of time of day training was observed on body mass and BMI. The magnitude of body mass and BMI decrease is is widely acceptable when compared to other studies. Indeed, there is a great variation in the loss of body mass in comparable studies: $1,4 \mathrm{Kg}, 4 \mathrm{Kg}, 6,2 \mathrm{Kg}, 6,7 \mathrm{Kg}$ with a maximum of 7,5 Kg body mass loss respectively in $\mathrm{M}$. Roussel et al [42], C.M. Beard et al [54], S. Ghroubi et al [53], S. Ghroubi et al (2009) [55] et R. Ross et al [56]. This dispersion is due to the variation in characteristics of studies' subjects, duration, intensity and shape of training program.

In general, $75 \%$ of weight loss after training program is fat mass loss independently from race, ethnic and age of subjects [57]. In this study, fat mass loss of both groups after training was greater than $75 \%$ of weight loss. In the MG, body fat mass loss $(5,6 \mathrm{Kg}, 15,9 \%)$ was quite equal to whole mass loss $(5,8 \mathrm{Kg}, 6 \%)$. In the EG, body fat mass loss $(8,8 \mathrm{Kg}, 24,9 \%)$ was even greater than whole mass loss $(7,1 \mathrm{Kg}, 7,3 \%)$. This means that in EG, the lean body mass increased. These amounts of fat loss in both groups are very important when compared with results of other studies. N. Mezghanni et al [58] measured a loss of 9,5\% and 14,4\% in fat mass respectively for a $50 \%$ of HRR and $75 \%$ of HRR intensity training for three months in obese. N. Mezghanni et al [58] training program has no strength training. The more fat mass loss we measured can due to strength training.

The EG fat mass loss was significantly greater than MG. The time of day training has an effect on fat mass loss. Training in the evening is more efficient than training in the morning for fat loss. The combined strength and aerobic endurance training we proposed permits fat oxidation during exercise and post exercise as we explained before. So, when we have training in the evening, fat oxidation periods coincides with best periods 
to fat oxidation which are: evening [17] and night [21]. This concomitance should give more efficiency to the evening training facing morning training [22].

Strength training is introduced in obese management essentially to preserve muscle mass against eventual atrophy caused by restrictive caloric diet [55]. Our results show that morning training permits to preserve lean mass whereas evening training permit a significant development of body lean mass $(2,8 \%)$. These results could be easily explained by the acrophase of strength development which occur in the evening [22]. Results concerning fat mass and body lean mass variation show that time of day training has a benefic effects on body composition in obese. The increase in lean body mass due to an essential increase in muscle mass didn't permit better results in 6 MWT for the EG. This reality can be justified since muscles groups trained in this study aren't directly used in the 6 MWT.

Waist circumference of both groups decreased significantly by $9 \mathrm{~cm}(8,2 \%)$ in $\mathrm{MG}$ and by $11,3 \mathrm{~cm}$ $(10,2 \%)$ in EG. This decrease show an important abdominal fat decrease when compared to results reported by K.J Melanson et al $(5,3 \mathrm{~cm})$ [59] and R. Ross et al $(6,5 \mathrm{~cm})$ [56]. And it can be considered as normal variation when compared to results reported by S. Ghroubi et al $(8,8 \mathrm{~cm})$ [53] and S. Ghroubi et al $(10,3 \mathrm{~cm})$ [55] in their combined strength and endurance training associated with diet in obese.

In conclusion, the time of day specific obese training on body composition and physical capacity showed that morning training is more efficient in changing body composition with increasing fat loss and body lean mass. Physical capacity has increased and body mass decreased similarly in both groups training. In this study we opted to a short term study of eight weeks, a long term study should better separate effects of time of day training in obese.

\section{References}

[1]. P. T. James, N. Rigby, and R. Leach, International Obesity Task Force The obesity epidemic, metabolic syndrome and future prevention strategies, Eur. J. Cardiovasc. Prev. Rehabil, 2004, 11, 3-8.

[2]. NHLBI, Obesity Task Force Clinical guidelines on the identification, evaluation, and treatment of overweight and obesity in adultsthe evidence report, Obes. Res, 1998, 6, 51S-209S.

[3]. A. Basdevant, L'obésité : origines et conséquences d'une épidémie, Comptes Rendus Biologies, August 2006, volume 329, issue 8, pages 562-569.

[4]. A. Basdevant, Obesity: Pathophysiological concepts, Joint Bone Spine, 2008, vol 75, p 665-666.

[5]. A. Basdevant, B. Guy-Grand, Médecine de l'obésité. Flammarion-Médecine Sciences, 2004, vol 1, p 431.

[6]. G.A Bray, L.A. Tartaglia, Medical strategies in the treatment of obesity, Nature 404, 2000, page 672-677.

[7]. M. Merrouche, B. Coffin, Obésité : prise en charge, indication et méthode de traitement endoscopique et chirurgical, EMCHEPATHO-Gastroentérologie, July 2005, volume 2, issue 3, page 189-200.

[8]. F. Brandou, M. Dumortier, P. Garandeau, J. Mercier, J.F. Brun, Effects of two-month rehabilitation program on substrate utilization during exercise in obese adolescents, Diabetes Metab, 2003, 29, 20-7.

[9]. O. Ben Ounis, M. Elloumi, M. Amri, Y. Trabelsi, G. Lac, Z. Tabka, Impact of training and hypocaloric diet on fat oxydation and body composition in obese adolescents. Sci Sports, 2009, volume 24, issues 3-4, pages 178-185.

[10]. S. Lazzer, Y. Boirie, C. Montaurier, J. Vernet, M. Meyer, M. Vermorel, A weight reduction program preserves fat-free mass but not metabolic rate in obese adolescents. Obes Res, 2004, 12 (2), 233-40.

[11]. G. Akbulut, N. Rakicioglu, The Effects of Diet and Physical Activity on Resting Metabolic Rate (RMR) Measured by Indirect Calorimetry, and Body Composition Assessment by Dual-Energy X-Ray Absorptiometry (DXA). Turk J Phys Med Re hab, 2012, 58:1-8.

[12]. B. Schaar, C. Moos-Thiele, P. Platen, Effects of exercise, diet, and a combination of exercise and diet in overweight and obese adults - A Meta-Analysis of the data, The Open Sports Medicine Journal, 2010, 4, 17-28.

[13]. S.N. Blair, T.S. Church, The fitness, obesity, and health equation: is physical activity the common denominator ? JAMA, 2004, 292(10):1232-1234.

[14]. H. Nielens, Place de l'activité physique dans le traitement de l'obésité, Congrès UCL d'endocrinologie-diabétologie, Bruxelles, Belgique (03/2004) 2005, vol. 124, n 3, p 60 .

[15]. C. Maffeis, M. Castellani, Physical activity: An effective way to control weight in children? Nutr Metab Cardiovasc Dis, 2007, volume 17, issue 5, pages 394-408.

[16]. J. Mercier, M. Dumortier, Anomalies musculaires dans l'obésité et le diabète de type 2: intérêt de l'activité physique, Revue Française des Laboratoires, 2003, volume 2003, issue 350, pages 25-30.

[17]. H. Mohebbi, M. Azizi, E. Tabari, Effect of time of day on MFO and Fatmax during exercise in obese and normal weight women, Series: Physical Education and Sport, 2011, Vol. 9, No 1, pages $69-79$.

[18]. A. Chwalibog, G. Thorbek, Energy expenditure and oxidation of carbohydrate and fat in humans during day and night, Thermochimica Acta, (2002), 394, 247-252.

[19]. R.A. Salata, D.B. Jarret, J.G. Verbalis, and A.G. Robinson, Vasopressin stimulation of adrenocorticotropin hormone (ACTH) in humans, Journal Clinical Investigations, 1988, 81, 766-774.

[20]. J. Mendoza, P. Pévet, E. Challet, High-fat feeding alters the clock synchronization to light, J Physiol (Lond), 2008, 586, 5901-5910.

[21]. J. Bass, J.S. Takahashi, Circadian Integration of Metabolism and Energetics, Science, 2010, Vol 330, 1349, DOI: 10.1126/science.1195027.

[22]. G. Atkinson, A. Coldwells, T. Reilly, J.M. Waterhouse, A comparison of circadian rhythms in work performance between physically active and inactive subjects, Ergonomics, 1993, 36, 273-281.

[23]. J.A. Horne, O. Östberg, A self-assessment questionnaire to determine morningness-eveningness in human circadien rhythms, Int. J. Chronobiol, 1976, 4, 97-110.

[24]. N. Ratamess, Body composition status and assessment, In: J.K. Ehrman (Ed.), ACSM Resource Manual for Exercise Testing and Prescription (sixth ed.), Lippincott Williams \& Wilkins (2010).

[25]. A.C. Utter, D.C, Nieman, A.N. Ward, D.E. Butterworth. Use of the leg-to-leg bioelectrical impedance method in assessing bodycomposition change in obese women, Am. J. Clin. Nutr, 1999, 69, 603-607. 
[26]. M.C. Pouliot, J.P. Despres, S. Lemieux, S. Moorjani, C. Bouchard, A. Tremblay, A. Nadeau, P.J, Lupien. Waist circumference and abdominal sagittal diameter: best simple anthropometric indexes of abdominal visceral adipose tissue accumulation and related cardiovascular risk in men and women, Am. J. Cardiol, 1994, 73 (7), 460-468.

[27]. A. Baillot, N. Vibarel-Rebot, A. Lecoq, D. Chadenas, Le test de marche de six minutes chez les femmes obèses : reproductibilité, intensité relative et relation avec la qualité de vie, Science \& Sports, 2009, 24(1), 1-8.

[28]. K. Beriault, A.C. Carpentier, C. Gagnon, J. Ménard, J.P. Baillargeon, J.L. Ardilouze, M.F. Langlois, Reproducibility of the 6-minute walk test in obese adults, Int J Sports Med, 2009, 30(10), 725-7.

[29]. American Thoracic Society (ATS Statement), Guidelines for the Six-Minute Walk Test, Am J Respir Crit Care Med, 2002, 166, 1117 .

[30]. J.M. Jakicic, B.H. Marcus, K.I. Gallagher, M. Napolitano, W. Lang, Effect of exercise duration and intensity on weight loss in overweight sedentary women, JAMA, 2003, 290, 1323-30.

[31]. N.A. Maffiuletti, F. Agosti, P.G. Marione, G. Silvestri, C.L. Lafortuna, A. Sartorio, Changes in body composition, physical performance and cardiovascular risk factors after a 3 week integrated body weight reduction program and after $1-y$ follow up in severely obese men and women, Eur J Clin Nutr, 2005, 59, 685-94.

[32]. K.J. Melanson, J. Dell'Olio, M.R. Carpenter, T.J. Angelopoulos, Changes in multiple health outcomes at 12 and 24 weeks resulting from 12 weeks of exercise counselling with or without dietary counselling in obese Adults, Nutrition, 2004, 20, 849-56.

[33]. R. Ross, I. Janssen, J. Dawson, A.M. Kungi, L.J. Kuk, L.S, Wong et al. Exercise-induced reduction in obesity and insulin resistance in women: a randomized controlled trial, Obes Res, 2004, Volume 12, Issue 5, pages 789-798.

[34]. W.H.M. Saris, S.N. Blair, M.A, Van Baak. How much physical activity is enough to prevent unhealthy weight gain? Outcome of the IASO 1st Stock Conference and consensus statement, Obes Rev, 2003, 4, 101-14.

[35]. World Health Organisation (WHO), Obesity: preventing and managing the global epidemic, Report of a WHO Consultation (WHO Technical Report Series 894), 2000.

[36]. W.H. Saris, Exercise with or without dietary restriction and obesity treatment, International Journal of Obesity and Related Metabolic Disorders, 1995, 19, S113-S116.

[37]. D.L. Ballor, \& E.T. Poehlman, Exercise-training enhances fat-free mass preservation during diet-induced weight loss: A metaanalytical finding, International Journal of Obesity and Related Metabolic Disorders, 1994, 18, 35-40.

[38]. K. Yamanouchi, T. Shinozaki, K. Chikada, T. Nishikawa, K. Ito, S. Shimizu, et al. Daily walking combined with diet therapy is a useful means for obese NIDDM patients not only to reduce body weight but also improve insulin sensitivity, Diabetes Care, 1995. $18,775-778$.

[39]. O. Hamdy, S. Porramatikul, E. Al-Ozairi, Metabolic obesity: the paradox between visceral and subcutaneous fat, Curr Diabetes Rev. 2006 Nov, 2(4), 367-73

[40]. Americain college of sports medicine, Stratégies d'intervention appropriées pour la perte de poids et la prévention de la reprise de poids chez les adultes, Med. Sci. Sports Exerc, 2001, 32 (12), 2145-2156.

[41]. World Health Organisation (WHO), Global Recommendations on Physical activity for Health, 2010.

[42]. M. Roussel, S. Garnier, S. Lemoine, I. Gaubert, L. Charbonnier, G. Auneau, P. Mauriège, Influence of a walking program on the metabolic risk profile of obese postmenopausal women, Menopause, 2009 May-Jun, 16(3), 566-75.

[43]. A. Berg, I. Frey, P. Deibert, et al. Gewichtsreduktion ist machbar, Ernahr Umsch, 2003, 10: 386-92.

[44]. A. Berg, I. Frey, U. Landmann, et al. Gewichtsreduktion durch Lebensstilintervention. Ernahr Umsch, 2005 , 8: 310-4.

[45]. R.W Bryner, R.C Toffle, I.H Ullrich, et al. The effects of exercise intensity on body composition, weight loss, and dietary composition in women, $J$ Am Coll Nutr, 1997; 1: 68-73.

[46]. G.A. Gaesser, and R.G Rich, Effects of high- and low-intensity exercise training on aerobic capacity and blood lipids, Med. Sci. Sports Exercise, 1984, 16, 269-274 18.

[47]. R. Bahr, and O.M. Sejersted, Effect of intensity of exercise on excess postexercise $\mathrm{O}_{2}$ consumption. Metab. Clin. Exp, 1991, 40, 83684.

[48]. C.A. Gilette, R.C. Bullough, and C.L. Melby, Postexercise energy expenditure in response to acute aerobic or resistance exercise. Int. J. Sport Nutr, 1994, 4, 347-360.

[49]. M.R. Mcguigan, M. Tatasciore, R.U. Newton, S. Pettigrew, Eight weeks of resistance training can significantly alter body composition in children who are overweight or obese, J. Strength Condit. Res, 2009, 23, 80-85.

[50]. J. Ibanez, M. Izquierdo, I. Arguelles, L. Forga, J.L. Larrion, M. Garcia-Unciti, F. Idoate, E.M. Gorostiaga, Twiceweekly progressive resistance training decreases abdominal fat and improves insulin sensitivity in oldermenwith type 2 diabetes, Diabetes Care, 2005, $28,662-667$.

[51]. S. Tsuzuku, T. Kajioka, H. Endo, R.D. Abbott, J.D. Curb, K. Yano, Favorable effects of non-instrumental resistance training on fat distribution and metabolic profiles in healthy elderly people, Eur. J. Appl. Physiol, 2007, 99, 549-555.

[52]. S.K. Park, J.H. Park, Y.C. Kwon, H.S. Kim, M.S. Yoon, H.T. Park, The effect of combined aerobic and resistance exercise training on abdominal fat in obese middle-aged women. J. Physiol. Anthropol. Appl. Hum. Sci, 2003, 22, 129-135.

[53]. S. Ghroubi, H. Elleuch, T. Chikh, N. Kaffel, M. Abid, M.H. Elleuch, Physical training combined with dietary measures in the treatment of adult obesity, A comparison of two protocols. Annales de réadaptation et de médecine physique, 2008, 51, 663-670.

[54]. C.M. Beard, R.J. Barnard, D.C. Robbins, J.M. Ordovas, E.J. Schaefer, Effects of diet and exercise on qualitative and quantitative measures of LDL and its susceptibility to oxidation, Arterioscler Thromb Vasc Biol, 1996, 16, 201-207.

[55]. S. Ghroubi, H. Elleuch, N. Kaffel, T. Echikh, M. Abid, M.H. Elleuch, Apport de l'exercice physique et du régime dans la prise en charge de la gonarthrose chez l'obèse, Annals of Physical and Rehabilitation Medicine, 2009, 52, 394-413.

[56]. R. Ross, D. Dagnone, P.J. Jones, H Smith, A Paddags, R Hudson, I Janssen, Reduction in obesity and related comorbid condition s after diet-induced weight loss or exercise-induced weight loss in men: A randomized, controlled trial, Ann Intern Med, 2000, Volume 133, Issue 2, pages 92-103.

[57]. L. Tappy, J.P. Felber, E. Jequier, Energy and substrate metabolism in obesity and post obese state, Diabetes Care, 1992, 14, 11801188.

[58]. N. Mezghanni, K. Chaabouni, H. Chtourou, L. Masmoudi, K. Chamari, A. Lassoued, M. Mnif, K. Jamoussi and H. Mejdoub, Effect of exercise training intensity on body composition, lipid profile, and insulin resistance in young obese women, African Journal of Microbiology Research, 2012, Vol. 6(10), pp. 2481-2488.

[59]. K.J. Melanson, J. Dell'Olio, M.R. Carpenter, T.J. Angelopoulos, Changes in multiple health outcomes at 12 and 24 weeks resulting from 12 weeks of exercise counselling with or without dietary counselling in obese Adults, Nutrition, 2004, 20, 849-56. 